\title{
A prevention programme for multiple health-compromising behaviors in adolescence: baseline results from a cluster randomized controlled trial
}

\section{Authors}

Elias Allara (1,2), Paola Angelini (3), Giuseppe Gorini (4), Sandra Bosi (5), Giulia Carreras (4), Cristina Gozzi (5), Andrea Martini (4), Marco Tamelli (5), Simone Storani (5), Fabrizio Faggiano (1)

(1) Department of Translational Medicine, Avogadro University, Novara, Italy

(2) School of Public Health, University of Torino, Torino, Italy

(3) Public Health Unit, Emilia-Romagna Regional Authority, Bologna, Italy

(4) Environmental and Occupational Epidemiology Unit, Cancer Prevention and Research Institute (ISPO), Florence, Italy

(5) Italian League against Cancer (LILT), Reggio Emilia, Italy

\section{Corresponding author}

Elias Allara

elias.allara@med.unipmn.it

+393485922753

Department of Translational Medicine, Avogadro University

Via Solaroli 17,

28100 Novara

Italy

Word count (background to conclusions): 3,550

Word count (abstract): 201

Date: 12 November 2014 


\section{Abstract}

Objective. To describe the design and present the baseline findings of the evaluation study of 'Paesaggi di Prevenzione', a school-based prevention programme tackling smoking, alcohol misuse, dietary risks, and physical inactivity in 12- to 14-year-olds.

Methods. The programme was implemented from January 2011 to April 2012 in Emilia-Romagna, Italy, and comprised classroom activities and school-wide policies. A two-arm cluster randomized controlled trial was designed. Schools were the units of randomization and were matched by socioeconomic status, size, and type.

Results. Data from 4700 middle school students and 2952 high school students were collected anonymously from October to December 2010. Past-30-day smoking prevalence was $1.9 \%$ among middle school students and $20.8 \%$ among high school students. Past-30-day prevalence of alcohol intoxication was $2.2 \%$ among middle school students and $11.4 \%$ among high school students. $39.7 \%$ of middle school students and $48.0 \%$ of high school students drank sugar-sweetened beverages four or more times per week. $7.5 \%$ of middle school students and $7.1 \%$ of high school students had intense physical activity every day.

Conclusions. This study seems adequately powered and baseline variables appear evenly distributed between study groups. Findings are in line with those of the WHO Health Behaviour in School-Aged Children study.

Trial registration: ISRCTN00953701.

\section{Keywords}

School-based prevention; Tobacco; Alcohol; Dietary risks; Eating behaviour; Physical activity; Cluster randomized controlled trial; Youth; Adolescence; Evidence-based prevention 


\section{Background}

Seven risk factors account for $56.1 \%$ of the attributable disability-adjusted life year (DALYs) in Western Europe: dietary risks, smoking, high blood pressure, high body mass index, physical inactivity, excessive alcohol consumption, and high fasting plasma glucose (Institute for Health Metrics and Evaluation, 2013).

In 2006 the WHO Regional Office for Europe started 'Gaining Health' (WHO Europe and WHO Regional Office for Europe, 2006), a policy framework aiming to contrast the main risk factors and socioeconomic determinants of non-communicable diseases in Europe. A political response followed in Italy (DPCM 4 Maggio, 2007) to encourage the dissemination of prevention programmes tackling health-compromising behaviours, with particular focus on smoking, alcohol misuse, dietary risks, and physical inactivity.

Schools are considered some of the most appropriate places for the implementation of prevention programmes (Centers for Disease Control and Prevention, 1994). Students attend school during their adolescence years, when some patterns of health-compromising behaviours may start to appear, and teachers are often willing to convey prevention messages. Evidence supports the effectiveness of some school-based interventions tackling alcohol misuse (Foxcroft and Tsertsvadze, 2012, 2011), dietary risks (Kremers et al., 2007), and sedentary behaviour (Kremers et al., 2007; van Sluijs et al., 2007). There is mixed evidence on the effectiveness of school-based smoking prevention interventions (Thomas and Perera, 2006), although a recent study provided promising results (Gorini et al., 2014).

Research shows that some risk behaviours, such as alcohol misuse, tobacco smoking, physical inactivity, and antisocial behaviour cluster in adolescence, both at a group level and at an individual level (Basen-Engquist et al., 1996; DuRant et al., 1999; Farhat et al., 2010; MacArthur et al., 2012; WHO Europe and WHO Regional Office for Europe, 2006), and that such behaviours are associated with increased and cumulative risk of poor educational attainment, morbidity and premature mortality (Khaw et al., 2008; Kvaavik et al., 2010). 
Although some programmes have targeted multiple risk behaviours simultaneously (Faggiano et al., 2008; Noar and Zimmerman, 2005), to our knowledge no evidence is available on universal interventions tackling simultaneously the four health-compromising behaviours which are the principal target of the 'Gaining Health' strategy in Italy.

The Regional Authority of Emilia-Romagna, an administrative area in Northern Italy (population in 2012: 4.3 million (Italian National Institute of Statistics (ISTAT), 2013)), is deeply engaged in the contrast of risk behaviours. Current public health activities encompass implementation of public health policies, such as a smoking ban at schools and healthcare facilities, and development of school-based prevention programmes, such as a successful programme tackling smoking initiation in adolescence - the Luoghi di Prevenzione-Prevention Grounds programme (LILT-LdP) (Bosi et al., 2013; Gorini et al., 2014).

This paper aims to describe the design and present the baseline findings of the evaluation study of 'Paesaggi di Prevenzione', a prevention programme developed by the Emilia Romagna Regional Authority on top of the LILT-LdP experience and tackling simultaneously smoking, alcohol misuse, dietary risks, and physical inactivity.

\section{Methods}

\section{The 'Paesaggi di Prevenzione' programme}

'Paesaggi di Prevenzione' is a multi-target prevention programme aimed at developing healthy lifestyles in 12 to 14 years old students (Bertini et al., 2006; Botvin et al., 1995). The programme aims to reduce initiation to tobacco smoking and alcohol misuse, improve the quality of diet, and increase frequency and intensity of physical activity. It was developed in two versions, one for middle school students (12 year olds) and one for high school students (14 year olds).

'Paesaggi di Prevenzione' is based on two components: (i) an interactive classroom curriculum delivered by trained teachers with the support of audio-visual media, and (ii) school policies 
developed by students, teachers, and families, and approved by the school authorities. Each component has specific manuals and materials available on the programme website (www.luoghidiprevenzione.it/PaesaggiDiPrevenzione/default.aspx).

The classroom component comprises four independent pathways, one for each behaviour targeted by the programme. Teachers can choose the pathways to implement, tailoring the programme to the specific needs of their students. Interactive classroom activities are intended to enhance decision making skills, problem solving, personal and interpersonal skills, management of stress and emotions, and effective communication. In this evaluation study, teachers $(n=271)$ were trained over three 4-hour sessions delivered by a group $(n=80)$ of public health professionals and lead teachers, whom were previously trained over two 8-hour sessions administered centrally at the Health Promotion centre of the Italian League against Cancer (LILT) in Reggio Emilia, Italy.

School policies comprise smoking bans for both student and teachers inside and outside school facilities, prohibition to use alcohol during school events, promotion of use of healthy foods in selling machines and canteens, walking activities involving families and local communities, and team games.

\section{Study design}

A two arm cluster randomized controlled trial was designed. The experimental group implemented 'Paesaggi di Prevenzione' from January 2011 to April 2012, and the control group was administered the usual school curriculum. Students from both study arms filled out a baseline survey from October to December 2010 and a post-intervention survey in May 2012. High school students were also administered a follow-up survey in May 2013, whilst middle school students could not as their standard course of study lasts three years in Italy.

\section{Units of analysis}

Students were the units of analysis. Schools were the unit of randomization. 


\section{Sample size}

The sample size was estimated conservatively on the basis of the targeted behaviour with the lowest anticipated prevalence at baseline, i.e. tobacco smoking. An overall sample size of 5200 middle school students and 3400 high school students was calculated assuming 5\% type I error $\left(z_{\alpha / 2}\right), 80 \%$ power $\left(z_{\beta}\right)$, and a different past-30-day smoking prevalence in the intervention and control groups. The anticipated smoking prevalence in the control group $\left(P_{2}\right)$ was obtained from 2009-2010 age-specific regional figures of the WHO Health Behaviour in School-aged Children (HBSC) study for Emilia Romagna (Angelini et al., 2010). Smoking prevalence in the experimental group $\left(P_{1}\right)$ was calculated assuming a $30 \%$ reduction in $P_{2}$ in the experimental group, in line with the three-month findings of another prevention programme tackling smoking and other risk behaviours (Faggiano et al., 2008). For middle schools $P_{1}$ was $7 \%$ and $P_{2}$ was $10 \%$. For high schools $P_{1}$ was $11 \%$ and $P_{2}$ was $15 \%$. An inflation factor (IF) of 1.9 was obtained via the formula $1+(m-1)$ $\times$ ICC, in which $\mathrm{m}$ is the average size of the cluster, assumed to be 25 students per class, and ICC is the intraclass correlation coefficient for past-30-day smoking, which was assumed to be 0.039 consistently with a previous study (Faggiano et al., 2007). The IF was applied to calculations of sample sizes for both middle schools and high schools.

$$
\text { Sample size }=2 \times \frac{\left(z_{\alpha / 2}+z_{\beta}\right)^{2}\left[P_{1}\left(1-P_{1}\right)+P_{2}\left(1-P_{2}\right)\right] \times I F}{\left(P_{1}-P_{2}\right)^{2}}
$$

The assumed ICC of 0.039 was compared with the ICC estimated from our baseline data (McGraw and Wong, 1996; Shrout and Fleiss, 1979).

\section{Eligibility of schools}

All urban state schools with four or more sections were candidate to enrolment. Middle schools were selected in 10 out of 11 Local Health Authorities of the Emilia-Romagna administrative area: Piacenza, Parma, Reggio Emilia, Bologna, Imola, Ravenna, Cesena, Rimini, Ferrara, Modena. High schools were selected from all of the above with the exception of the Authority of Reggio Emilia, which was already participating to another trial (Bosi et al., 2013; Gorini et al., 2014). 


\section{Eligibility of students}

All students attending the participating schools were included in the survey, with the exception of those who were unable to participate in the survey due to general learning disability.

\section{Randomization and allocation concealment}

Schools were stratified by socio-economic status, size, and type (i.e., middle schools and high schools) to form strata of schools presenting similar characteristics. High schools were also stratified by subtype, i.e. vocational or preparatory. Within each stratum, schools were randomly assigned to the experimental or control arm using a computer-generated list of random numbers. The allocation procedure was carried out centrally by independent contractors, Avogadro University and the Cancer Prevention and Research Institute (ISPO), which did not know the schools nor lived in the administrative area where the programme was implemented.

\section{Outcome measures}

We obtained student-level information on self-reported behavioural outcomes, possible mediators, and socio-demographic characteristics. Students from both study arms filled out an anonymous baseline survey from October to December 2010 and an anonymous post-intervention survey in May 2012. High school students were also administered an anonymous follow-up survey in May 2013, whilst middle school students could not as their standard course of study lasts three years in Italy.

Behavioural outcome variables were selected among those commonly used in the literature (Angelini et al., 2010; Currie et al., 2008; Faggiano et al., 2007; Sloboda et al., 2009). Students were asked about the number of days per month they smoked cigarettes or experienced alcohol intoxication.

Due to the multifaceted effects of eating behaviours on health, it is difficult to distinguish between healthy and unhealthy eating behaviours. Students were asked how many days per week they used 
to eat fruit, vegetables, snacks, crisps, cakes and ice creams, fish, legumes, milk or yogurt, meat or dairy products; had breakfast; used to drink sugar-sweetened beverages. Due to the need to come up with a reasonable number of indicators and thus avoid potential inflating of type I errors (Benjamini and Hochberg, 1995), and consistently with the Italian Dietary Guideline (National Institute of Research for Food and Nutrition (INRAN), 2003) and with previous works (Perry et al., 2004, 1998), we hypothesized that 'Paesaggi di prevenzione' would have reduced some particular behaviours (such as drinking sugar-sweetened beverages; eating crisps and snacks; eating cakes and ice creams), whilst encouraging others (e.g., eating fruit and vegetables; having regular breakfast every day). In this paper we have therefore focused on such behaviours.

Students were also asked how many days per week and how many hours per day they did moderate or vigorous physical activity, as defined in the HBSC study and consistently with previous work (Bayne-Smith et al., 2004; Robbins et al., 2006): 'any activity that increases your heart rate and makes you get out of breath some of the time for at least 60 minutes', and how many hours per day they watched TV and used computers or videogames (Currie et al., 2008) and consistently with. A copy of the questionnaire in Italian can be requested from the authors.

Based on the assumed theoretical model, the main mediators of behavioural effect were also measured to allow exploring of possible mediation effects.

\section{Variations from study protocol}

Just after the randomization procedure and before the start of the programme, three control schools implementing other prevention activities were switched to the intervention group. Such schools $(n=3)$ and their matched counterparts $(n=3)$ were therefore excluded from the analyses.

In one stratum both schools were implementing other prevention interventions and their allocation was not changed because they appeared to be balanced with regard to the amount, quality and intensity of the ongoing interventions. Such pair of school was kept in the analyses. 


\section{Drop-outs}

Schools - Three middle schools and three high schools allocated to the intervention group opted out just after randomization as their teachers were already committed to other activities. This resulted in exclusion of their matched control schools. Due to the exitus of the teacher appointed to leading the implementation of the programme, one middle school dropped out after the baseline survey was administered. This school and its control were excluded from analyses.

Classes - One middle-school class in the control arm and one high-school class in the intervention arm dropped out after randomization and before the administration of the baseline survey due to other commitments of the teachers.

\section{Statistical methods}

We carried out a descriptive analysis of the baseline characteristics by study arm. Chi-squared tests were performed to test differences in prevalence of categorical variables. T-tests were used to test differences in mean of continuous variables. We conducted separate analyses for middle schools and for high schools.

\section{Ethics}

The study was registered on www.controlled-trials.com with number ISRCTN00953701 and was approved by the Ethics Committee of the Local Health Authority of Reggio Emilia, Italy, with resolution number 0033/DS. A copy of the protocol can be requested from the authors. Parents and carers were informed of the 'Paesaggi di Prevenzione' trial and students had the option to opt out at any moment. All data were collected anonymously. In order to link the baseline questionnaire with the post-intervention questionnaire, we used a 9-digit unique code generated by the students which was already used successfully in other trials (Faggiano et al., 2008; Galanti et al., 2007; Gorini et al., 2014). 


\section{Results}

\section{Enrolment and respondents}

At the end of the enrolment process, 54 middle schools were sampled and 44 could be included (Figure 1). 4700 out of 5147 eligible middle school students (91.3\%) filled out the baseline questionnaire.

Forty-four high schools were sampled, and 34 could be included (Figure 2). 2952 out of 3349 eligible high school students (88.2\%) filled out the baseline questionnaire.

\section{Characteristics of the enrolled population}

Middle schools - Mean age in the sample of middle schools was 12.1 years old (standard deviation [SD] 0.45 ) (Table 1). Around $49.1 \%$ were girls. Nearly $85.4 \%$ of the students came from families with medium or high socio-economic status (SES). About $85.2 \%$ of the students in the intervention group and $82.2 \%$ of the students in the control group $(p=0.005)$ had at least one parent of Italian descent.

High schools - Mean age was 14.3 years old (SD 0.68). Nearly $47.4 \%$ of the students in the intervention group and $41.8 \%$ of the students in the control group were girls $(p=0.003)$. Nearly $82.4 \%$ of the students came from families with medium or high SES. Almost $85.1 \%$ had at least one parent of Italian descent.

\section{Tobacco smoking}

Middle schools - Around $1.9 \%$ of the students smoked at least once in the past 30 days, and $0.5 \%$ smoked at least 20 times (Table 2).

High schools - Approximately $20.8 \%$ of the students smoked at least once in the past 30 days, with some evidence of a greater prevalence $(p=0.046)$ in the intervention group $(22.5 \%)$ compared to the control group (19.4\%). 8.8\% of the students smoked at least 20 times in the previous month. 


\section{Alcohol misuse}

Middle schools - Prevalence of past-month alcohol intoxication was 2.2\% (Table 2). There was some evidence $(p=0.050)$ of greater prevalence of post-month frequent (three or more) episodes of intoxication among students in the control arm (1.1\%) compared to students in the intervention $\operatorname{arm}(0.6 \%)$.

High schools - Prevalence of past-month alcohol intoxication was $11.4 \%$. Past-month frequent intoxication was observed in $4.1 \%$ of the students.

\section{Eating behaviour}

Middle schools - Approximately four students out of ten used to eat fruit every day (Table 3), and one third used to eat vegetables every day. More than seventy-percent had breakfast every day. With regards to unhealthy behaviours, $39.7 \%$ used to drink sugar-sweetened beverages, $34.5 \%$ used to eat crisps and snacks, and $37.7 \%$ used to eat cakes and ice creams four or more times per week. The mean score of eating behaviour was 3.6 (SD 1.41), i.e. in the upper half of the range.

High schools - Approximately one third of the students used to eat fruit and to eat vegetables every day. Nearly sixty-percent had breakfast every day. $48.0 \%$ used to drink sugar-sweetened beverages, $39.1 \%$ used to eat crisps and snacks, and $41.4 \%$ used to eat cakes and ice creams four or more times per week. The mean score of eating behaviour was 3.2 (SD 1.43), i.e. in the lower half of the range.

\section{Physical activity and sedentary behaviour}

Middle schools - Nearly $14.4 \%$ of the students had at least 60 minutes of physical activity and 7.5\% had intense physical activity, defined as 'physical activity that makes you out of breath or warmer than usual', every day (Table 3). Nearly one third used to watch television three or more hours per day, and nearly twenty-nine percent used computers or videogames three or more hours per day. 
High schools - Nearly $15.0 \%$ of the students had at least 60 minutes of physical activity and $7.1 \%$ had intense physical activity every day. More than one third of the students used to watch television three or more hours per day, and nearly forty-four percent used computers or videogames three or more hours per day.

\section{Intracluster correlation}

Intraclass correlation coefficients (ICCS) were calculated separately for middle schools and high schools, and for each of the 12 outcome variables presented in this paper (see Appendix 1 for further details). Out of 24 ICCs, 19 were smaller or much smaller than 0.039, i.e. the ICC anticipated when we carried out sample size calculations. Four ICCs were slightly greater and were ranging from 0.040 to 0.052 . One ICC was equal to 0.086 and referred to past-30-day smoking among high school students.

\section{Discussion}

To our knowledge, this is the first Italian study aiming to assess the effectiveness of a school-based prevention programme simultaneously targeting smoking, alcohol misuse, eating behaviour, and sedentary behaviour. This study involved 7652 students and mobilised resources in one of the most populated administrative areas in Italy.

After exclusion of schools which violated the protocol or opted out, the sample size for middle schools was around $90 \%$ of the anticipated sample size (4700/5200), and the sample size for high schools was approximately $87 \%$ of the anticipated sample size (2952/3400). Sample size calculations were conservative and based on the prevalence of tobacco smoking, which was the least prevalent behaviour among those targeted by 'Paesaggi di Prevenzione'. Therefore, the sample size of this study appears to provide acceptable power for detecting changes in the risk behaviours addressed by the programme. 
In general, baseline and sociodemographic characteristics appear to be balanced between study groups. Some imbalance is noted for two variables (out of seventeen) for each type of schools. Differences in such variables appear small in size and their level of statistical significance might be due to the large sample size. Analyses accounting for the clustering due to individuals belonging to the same school might estimate larger standard errors, which would likely result in low or no evidence of a difference in baseline variables. Whenever needed, later analyses should however account for the potential confounding effects of baseline variables. Adjustment for potential confounders is common practice in cluster randomized controlled trials, in which allocation is not conducted at an individual level (see, for example, (Faggiano et al., 2010, 2008)).

Prevalence of behavioural outcomes are in line with the findings of the 2009-2010 Health Behaviour in School-aged Children (HBSC) survey (Angelini et al., 2010), with the exception of three indicators. Students enrolled in this study appeared to experiment alcohol intoxication less often and to practice physical activity more often than their HBSC counterparts, whilst eating less fruit ${ }^{1}$. A sample composed by healthier subjects could potentially hinder the ability to detect a behavioural change due to the 'Paesaggi di Prevenzione' programme. However, the differences in prevalence of behavioural outcomes between this study and the HBSC study were small in most cases, and the conservative sample calculations we carried out are likely to provide sufficient power.

For most behaviours, intracluster correlations coefficients (ICCS) are lower or much lower than the ICC anticipated when carrying out sample size calculations. The estimated ICCs therefore seem unlikely to affect the ability of the study to detect changes in most of the behaviours targeted by 'Paesaggi di Prevenzione', although some caution might be needed in interpreting programme effects on smoking behaviour of high-school children. However, it is worth noting that another Italian study (Gorini et al., 2014), which based its sample size calculations on the same ICC anticipated in our study, found evidence of a programme effect on past-30-day smoking behaviour

\footnotetext{
${ }^{1}$ Prevalence of alcohol misuse was lower in this study than in the HBSC study $(5.0 \%$ among eleven years old, $8.4 \%$ among thirteen years old, and 25.0\% among fifteen years old)(Angelini et al., 2010). Prevalence of daily physical activity for at least 60 minutes was considerably greater in this study among both middle and high school students than in the HBSC study (7.0\% among eleven years old, 6.5 among thirteen years old, and 6.8 among fifteen years old). However, prevalence of daily fruit consumption was lower in this study than in the HBSC study (44.4\% among eleven years old, 40.4\% among thirteen years old, and 40.8\% among fifteen years old).
} 
among high-school children. This may be partly due to the fact that smoking prevalence increases with age, thus requiring a smaller sample size to detect the same effect size. The anticipated sample size for high school children may therefore be sufficient for detecting a post-intervention change in smoking behaviour due to 'Paesaggi di Prevenzione' among high-school children.

Currently, only a few school-based prevention programmes were found effective after rigorous evaluation. This is partly due to the common perception that carrying out an accurate and adequately powered evaluation study may be impracticable without considerable funding. This misconception has a negative impact both on research, by hindering the advancement of prevention science, and on practice, by reducing the supply of effective prevention programmes. This study may also serve to show that conducting a large randomized trial for the evaluation of a prevention programme is feasible even without specific funding, provided that the local health authorities and their public health professionals are committed to the project.

In general, this paper shows that the sample size and the distributions of study variables may be appropriate for the evaluation of the 'Paesaggi di Prevenzione' programme, provided that statistical analyses do not fail to account for possible confounding effects.

\section{List of abbreviations}

DALY: disability-adjusted life year

WHO: World Health Organization

HBSC: Health Behaviour in School-Aged Children

SES: socio-economic status

SD: standard deviation 


\section{Acknowledgements}

The authors are grateful to the Regional Health Authority of Emilia-Romagna for their strong commitment and support, to the local health professionals who were responsible for the training and monitoring of the programme, to the teachers involved in the programme, and to the school authorities.

\section{Competing interests}

The authors declare that there are no conflicts of interest.

\section{Funding}

No specific funding was available for this study. The design and analysis of the study were assigned to external contractors, Avogadro University and the Cancer Prevention and Research Institute (ISPO), supported by the Italian League against Cancer (LILT), Reggio Emilia, Italy. 


\section{References}

Angelini, P., Baldacchini, F., Mignani, R., 2010. Stili di vita e salute dei giovani in età scolare. Rapporto sui dati regionali HBSC 2009-2010 Regione Emilia-Romagna.

Basen-Engquist, K., Edmundson, E.W., Parcel, G.S., 1996. Structure of health risk behavior among high school students. J. Consult. Clin. Psychol. 64, 764-775. doi:10.1037/0022-006X.64.4.764

Bayne-Smith, M., Fardy, P.S., Azzollini, A., Magel, J., Schmitz, K.H., Agin, D., 2004. Improvements in heart health behaviors and reduction in coronary artery disease risk factors in urban teenaged girls through a school-based intervention: the PATH program. Am. J. Public Health 94, 153843.

Benjamini, Y., Hochberg, Y., 1995. Controlling the False Discovery Rate: A Practical and Powerful Approach to Multiple Testing. J. R. Stat. Soc. Ser. B 57, 289-300. doi:10.2307/2346101

Bertini, M., Braibanti, P., Gagliardi, M.P., 2006. Il modello «Skills for life» 11-14 anni. La promozione dello sviluppo personale e sociale nella scuola. Franco Angeli, Milano.

Bosi, S., Gorini, G., Tamelli, M., Monti, C., Storani, S., Carreras, G., Martini, A., Allara, E., Angelini, P., Faggiano, F., 2013. A school-based peer-led smoking prevention intervention with extracurricular activities: the LILT-LdP cluster randomized controlled trial design and study population. Tumori 99, 572-7. doi:10.1700/1377.15304

Botvin, G.J., Baker, E., Dusenbury, L., Botvin, E.M., Diaz, T., 1995. Long-term follow-up results of a randomized drug abuse prevention trial in a white middle-class population. JAMA 273, 110612.

Centers for Disease Control and Prevention, 1994. Guidelines for school health programs to prevent tobacco use and addiction.

Currie, C., Gabhainn, S.N., Godeau, E., Roberts, C., Smith, R., Currie, D., Picket, W., Richter, M., Morgan, A., Barnekow, V., 2008. Inequalities in young people's health. HBSC international report from the 2005/2006 survey.

DPCM 4 Maggio, 2007. Documento programmatico “Guadagnare salute”. Presidenza del Consiglio dei Ministri.

DuRant, R.H., Smith, J. a, Kreiter, S.R., Krowchuk, D.P., 1999. The relationship between early age of onset of initial substance use and engaging in multiple health risk behaviors among young adolescents. Arch. Pediatr. Adolesc. Med. 153, 286-91. 
Faggiano, F., Galanti, M.R., Bohrn, K., Burkhart, G., Vigna-Taglianti, F., Cuomo, L., Fabiani, L., Panella, M., Perez, T., Siliquini, R., van der Kreeft, P., Vassara, M., Wiborg, G., 2008. The effectiveness of a school-based substance abuse prevention program: EU-Dap cluster randomised controlled trial. Prev. Med. (Baltim). 47, 537-43.

doi:10.1016/j.ypmed.2008.06.018

Faggiano, F., Richardson, C., Bohrn, K., Galanti, M.R., 2007. A cluster randomized controlled trial of school-based prevention of tobacco, alcohol and drug use: the EU-Dap design and study population. Prev. Med. (Baltim). 44, 170-3. doi:10.1016/j.ypmed.2006.09.010

Faggiano, F., Vigna-Taglianti, F., Burkhart, G., Bohrn, K., Cuomo, L., Gregori, D., Panella, M., Scatigna, M., Siliquini, R., Varona, L., van der Kreeft, P., Vassara, M., Wiborg, G., Galanti, M.R., 2010. The effectiveness of a school-based substance abuse prevention program: 18-month follow-up of the EU-Dap cluster randomized controlled trial. Drug Alcohol Depend. 108, 56-64. doi:10.1016/j.drugalcdep.2009.11.018

Farhat, T., lannotti, R.J., Simons-Morton, B.G., 2010. Overweight, obesity, youth, and health-risk behaviors. Am. J. Prev. Med. 38, 258-67. doi:10.1016/j.amepre.2009.10.038

Foxcroft, D.R., Tsertsvadze, A., 2011. Universal school-based prevention programs for alcohol misuse in young people. Cochrane database Syst. Rev. CD009113. doi:10.1002/14651858.CD009113

Foxcroft, D.R., Tsertsvadze, A., 2012. Universal alcohol misuse prevention programmes for children and adolescents: Cochrane systematic reviews. Perspect. Public Health 132, 128-34. doi:10.1177/1757913912443487

Galanti, M.R., Siliquini, R., Cuomo, L., Melero, J.C., Panella, M., Faggiano, F., 2007. Testing anonymous link procedures for follow-up of adolescents in a school-based trial: the EU-DAP pilot study. Prev. Med. (Baltim). 44, 174-177. doi:10.1016/j.ypmed.2006.07.019

Gorini, G., Carreras, G., Bosi, S., Tamelli, M., Monti, C., Storani, S., Martini, A., Allara, E., Angelini, P., Faggiano, F., 2014. Effectiveness of a school-based multi-component smoking prevention intervention: The LdP cluster randomized controlled trial. Prev. Med. (Baltim). doi:10.1016/j.ypmed.2014.01.004

Institute for Health Metrics and Evaluation, 2013. GBD Compare [WWW Document]. URL http://viz.healthmetricsandevaluation.org/gbd-compare/ (accessed 1.28.14).

Italian National Institute of Statistics (ISTAT), 2013. Bilancio demografico 2012.

Khaw, K.-T., Wareham, N., Bingham, S., Welch, A., Luben, R., Day, N., 2008. Combined impact of health behaviours and mortality in men and women: the EPIC-Norfolk prospective population study. PLoS Med. 5, e12. doi:10.1371/journal.pmed.0050012 
Kremers, S.P.J., de Bruijn, G.-J., Droomers, M., van Lenthe, F., Brug, J., 2007. Moderators of environmental intervention effects on diet and activity in youth. Am. J. Prev. Med. 32, 163-72. doi:10.1016/j.amepre.2006.10.006

Kvaavik, E., Batty, G.D., Ursin, G., Huxley, R., Gale, C.R., 2010. Influence of individual and combined health behaviors on total and cause-specific mortality in men and women: the United Kingdom health and lifestyle survey. Arch. Intern. Med. 170, 711-8. doi:10.1001/archinternmed.2010.76

MacArthur, G.J., Smith, M.C., Melotti, R., Heron, J., Macleod, J., Hickman, M., Kipping, R.R., Campbell, R., Lewis, G., 2012. Patterns of alcohol use and multiple risk behaviour by gender during early and late adolescence: the ALSPAC cohort. J. Public Health (Oxf). 34 Suppl 1, i2030. doi:10.1093/pubmed/fds006

McGraw, K.O., Wong, S.P., 1996. Forming inferences about some intraclass correlation coefficients. Psychol. Methods 1, 30.

National Institute of Research for Food and Nutrition (INRAN), 2003. Linee guida per una sana alimentazione italiana [WWW Document]. URL http://nut.entecra.it/648/linee_guida.html

Noar, S.M., Zimmerman, R.S., 2005. Health Behavior Theory and cumulative knowledge regarding health behaviors: are we moving in the right direction? Health Educ. Res. 20, 275-90. doi:10.1093/her/cyg113

Perry, C.L., Bishop, D.B., Taylor, G., Murray, D.M., Mays, R.W., Dudovitz, B.S., Smyth, M., Story, M., 1998. Changing fruit and vegetable consumption among children: the 5-a-Day Power Plus program in St. Paul, Minnesota. Am. J. Public Health 88, 603-9.

Perry, C.L., Bishop, D.B., Taylor, G.L., Davis, M., Story, M., Gray, C., Bishop, S.C., Mays, R.A.W., Lytle, L.A., Harnack, L., 2004. A Randomized School Trial of Environmental Strategies to Encourage Fruit and Vegetable Consumption among Children. Heal. Educ. Behav. 31, 65-76. doi:10.1177/1090198103255530

Robbins, L.B., Gretebeck, K.A., Kazanis, A.S., Pender, N.J., 2006. Girls on the move program to increase physical activity participation. Nurs. Res. 55, 206-16.

Shrout, P.E., Fleiss, J.L., 1979. Intraclass correlations: uses in assessing rater reliability. Psychol. Bull. $86,420$.

Sloboda, Z., Stephens, R.C., Stephens, P.C., Grey, S.F., Teasdale, B., Hawthorne, R.D., Williams, J., Marquette, J.F., 2009. The Adolescent Substance Abuse Prevention Study: A randomized field trial of a universal substance abuse prevention program. Drug Alcohol Depend. 102, 1-10. doi:10.1016/j.drugalcdep.2009.01.015 
Thomas, R., Perera, R., 2006. School-based programmes for preventing smoking. Cochrane Database Syst. Rev. CD001293. doi:10.1002/14651858.CD001293.pub2

Van Sluijs, E.M.F., McMinn, A.M., Griffin, S.J., 2007. Effectiveness of interventions to promote physical activity in children and adolescents: systematic review of controlled trials. BMJ 335, 703. doi:10.1136/bmj.39320.843947.BE

WHO Europe, WHO Regional Office for Europe, 2006. Gaining Health The European Strategy for the Prevention and Control of Noncommunicable Diseases. Copenhagen, Denmark. 
Figure 1. Enrolment of middle school students

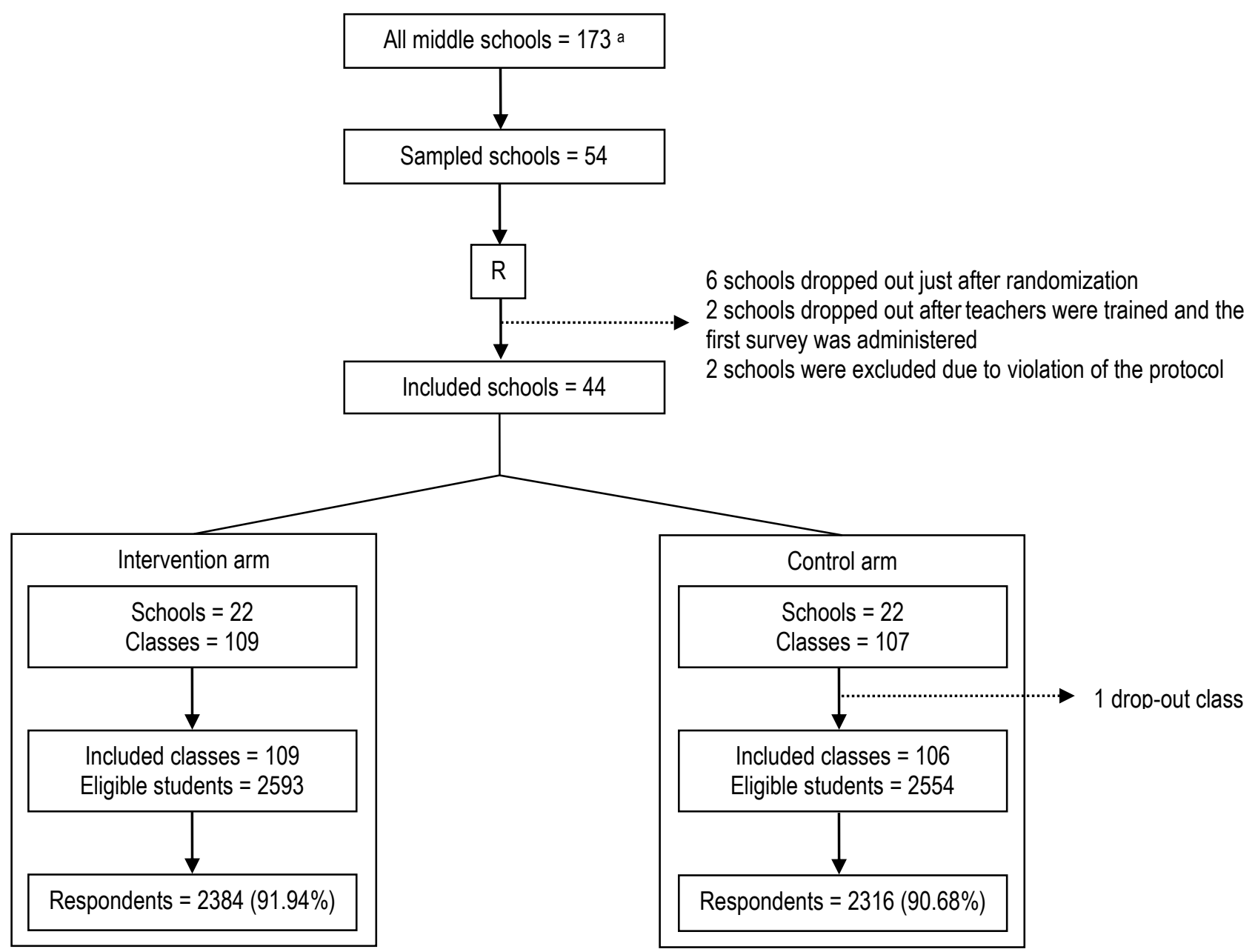

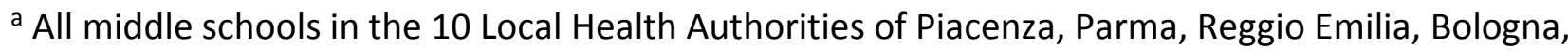
Imola, Ravenna, Cesena, Rimini, Ferrara, Modena 
Figure 2. Enrolment of high school students

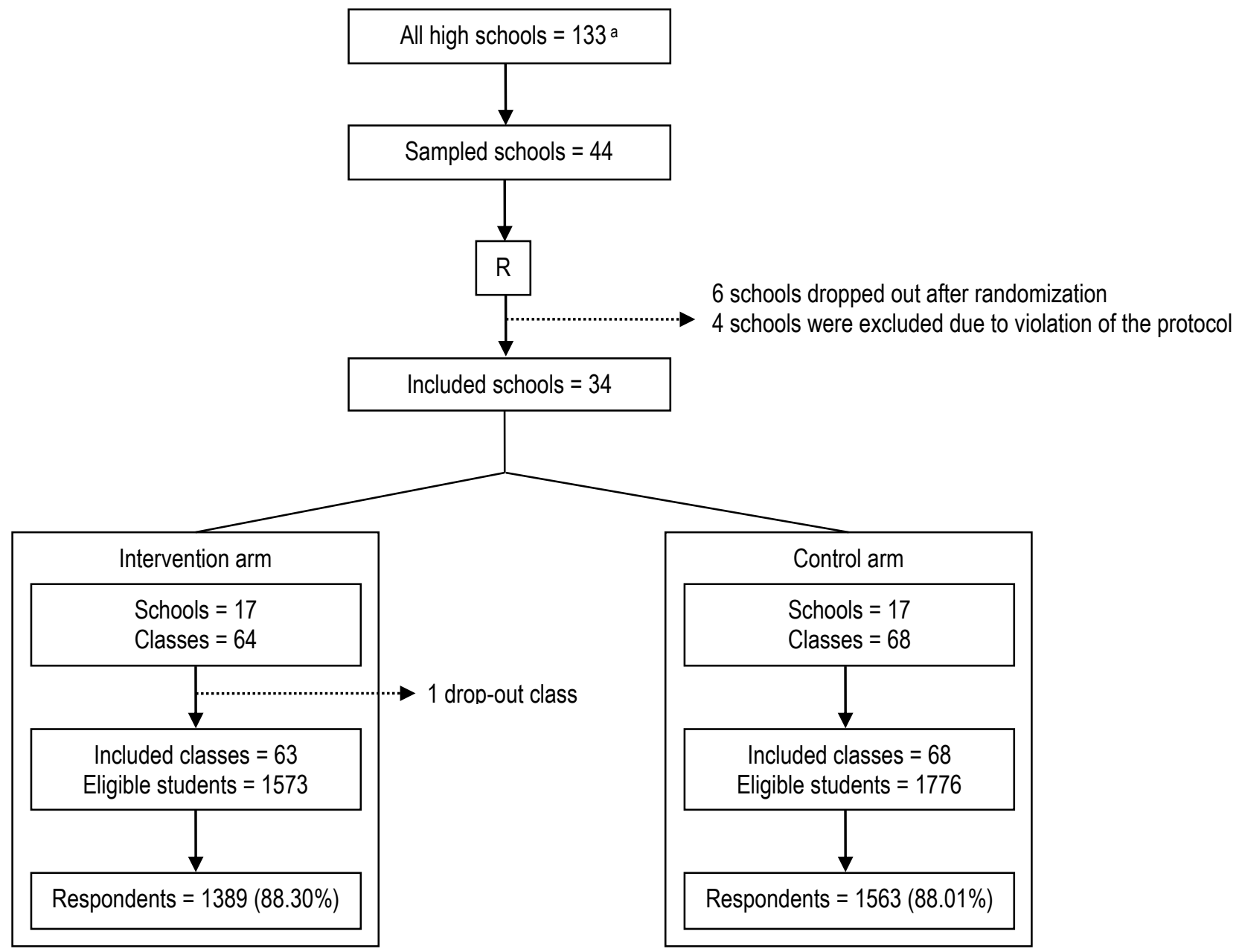

${ }^{\text {a }}$ All high schools in the 9 Local Health Authorities of Piacenza, Parma, Bologna, Imola, Ravenna, Cesena, Rimini, Ferrara, Modena. 
Table 1. Baseline socio-demographic characteristics in recruited students by study arm

\begin{tabular}{|c|c|c|c|c|c|c|c|c|}
\hline & \multicolumn{4}{|c|}{ Middle schools } & \multicolumn{4}{|c|}{ High schools } \\
\hline & $\begin{array}{l}\text { Intervention } \\
(\mathrm{N}=2384)\end{array}$ & $\begin{array}{c}\text { Control } \\
(\mathrm{N}=2316)\end{array}$ & $\begin{array}{c}\text { Total } \\
(\mathrm{N}=4700)\end{array}$ & $p$-value ${ }^{a}$ & $\begin{array}{l}\text { Intervention } \\
(\mathrm{N}=1389)\end{array}$ & $\begin{array}{c}\text { Control } \\
(\mathrm{N}=1563)\end{array}$ & $\begin{array}{c}\text { Total } \\
(\mathrm{N}=2952)\end{array}$ & $p$-value \\
\hline Age in years (mean (SD)) & $\begin{array}{l}12.08 \\
(0.41)\end{array}$ & $\begin{array}{l}12.10 \\
(0.49)\end{array}$ & $\begin{array}{l}12.09 \\
(0.45)\end{array}$ & 0.127 & $\begin{array}{l}14.30 \\
(0.68)\end{array}$ & $\begin{array}{l}14.31 \\
(0.68)\end{array}$ & $\begin{array}{l}14.31 \\
(0.68)\end{array}$ & 0.539 \\
\hline \multicolumn{9}{|l|}{$\operatorname{Sex}(n(\%))$} \\
\hline $\begin{array}{r}\text { Females } \\
\text { Males }\end{array}$ & $\begin{array}{c}1171 \\
(49.79) \\
1181 \\
(50.21)\end{array}$ & $\begin{array}{c}1101 \\
(48.46) \\
1171 \\
(51.54)\end{array}$ & $\begin{array}{c}2272 \\
(49.13) \\
2352 \\
(50.87)\end{array}$ & 0.367 & $\begin{array}{c}652 \\
(47.35) \\
725 \\
(52.65)\end{array}$ & $\begin{array}{c}642 \\
(41.80) \\
894 \\
(58.20)\end{array}$ & $\begin{array}{c}1294 \\
(44.42) \\
1619 \\
(55.58)\end{array}$ & 0.003 \\
\hline \multicolumn{9}{|l|}{$\begin{array}{l}\text { Socio-economic status } \\
\text { (n (\%)) }\end{array}$} \\
\hline $\begin{array}{r}\text { Medium } \\
\text { High }\end{array}$ & $\begin{array}{c}335 \\
(14.96) \\
1016 \\
(45.38) \\
888 \\
(39.66)\end{array}$ & $\begin{array}{c}305 \\
(14.17) \\
933 \\
(43.36) \\
914 \\
(42.47)\end{array}$ & $\begin{array}{c}640 \\
(14.58) \\
1949 \\
(44.39) \\
1802 \\
(41.04)\end{array}$ & 0.166 & $\begin{array}{c}253 \\
(18.97) \\
669 \\
(50.15) \\
412 \\
(30.88)\end{array}$ & $\begin{array}{c}248 \\
(16.46) \\
773 \\
(51.29) \\
486 \\
(32.25)\end{array}$ & $\begin{array}{c}501 \\
(17.63) \\
1442 \\
(50.76) \\
898 \\
(31.61)\end{array}$ & 0.210 \\
\hline \multicolumn{9}{|l|}{ Origin $(n(\%))$} \\
\hline $\begin{array}{r}\text { A least one parent is } \\
\text { Italian } \\
\text { Both parents are non- } \\
\text { Italian }\end{array}$ & $\begin{array}{c}2026 \\
(85.20) \\
352 \\
(14.80) \\
\end{array}$ & $\begin{array}{c}1898 \\
(82.20) \\
411 \\
(17.80) \\
\end{array}$ & $\begin{array}{c}3924 \\
(83.72) \\
763 \\
(16.28) \\
\end{array}$ & 0.005 & $\begin{array}{c}1173 \\
(84.88) \\
209 \\
(15.12) \\
\end{array}$ & $\begin{array}{c}1326 \\
(85.22) \\
230 \\
(14.78) \\
\end{array}$ & $\begin{array}{c}2499 \\
(85.06) \\
439 \\
(14.94) \\
\end{array}$ & 0.796 \\
\hline
\end{tabular}

${ }^{a}$ Comparisons between study groups. T-test for age; chi-squared tests for other variables

${ }^{b}$ Low $=$ both parents or guardians have a middle school or elementary qualification. Medium = at least one parent or guardian has a high school qualification; the other may have a lower qualification. High = at least one parent or guardian has a university degree; the other may have a lower qualification 
Table 2. Baseline prevalence of cigarette smoking and alcohol misuse in recruited students by study arm

\begin{tabular}{|c|c|c|c|c|c|c|c|c|}
\hline & \multicolumn{4}{|c|}{ Middle schools } & \multicolumn{4}{|c|}{ High schools } \\
\hline & $\begin{array}{c}\text { Intervention } \\
(\mathrm{N}=2384)\end{array}$ & $\begin{array}{c}\text { Control } \\
(\mathrm{N}=2316)\end{array}$ & $\begin{array}{c}\text { Total } \\
(\mathrm{N}=4700)\end{array}$ & $p$-value ${ }^{a}$ & $\begin{array}{c}\text { Intervention } \\
(\mathrm{N}=1389)\end{array}$ & $\begin{array}{c}\text { Control } \\
(\mathrm{N}=1563)\end{array}$ & $\begin{array}{c}\text { Total } \\
(\mathrm{N}=2952) \\
\end{array}$ & $p$-value ${ }^{a}$ \\
\hline \multicolumn{9}{|l|}{$\begin{array}{l}\text { Past-30-day tobacco } \\
\text { smoking (\%) }\end{array}$} \\
\hline Current smoker ( $1+$ times) & $\begin{array}{c}41 \\
(1.83)\end{array}$ & $\begin{array}{c}44 \\
(2.05)\end{array}$ & $\begin{array}{c}85 \\
(1.94)\end{array}$ & 0.606 & $\begin{array}{c}291 \\
(22.47)\end{array}$ & $\begin{array}{c}283 \\
(19.38)\end{array}$ & $\begin{array}{c}574 \\
(20.83)\end{array}$ & 0.046 \\
\hline Frequent smoker (20+) & $\begin{array}{c}8 \\
(0.36)\end{array}$ & $\begin{array}{c}12 \\
(0.56)\end{array}$ & $\begin{array}{c}20 \\
(0.46)\end{array}$ & 0.324 & $\begin{array}{c}105 \\
(8.11)\end{array}$ & $\begin{array}{c}136 \\
(9.32)\end{array}$ & $\begin{array}{c}241 \\
(8.75)\end{array}$ & 0.263 \\
\hline \multicolumn{9}{|l|}{$\begin{array}{l}\text { Past-30-day alcohol misuse } \\
(\%)\end{array}$} \\
\hline $\begin{array}{r}\text { Current alcohol intoxication } \\
(1+\text { times })\end{array}$ & $\begin{array}{c}44 \\
(1.97)\end{array}$ & $\begin{array}{c}53 \\
(2.48)\end{array}$ & $\begin{array}{c}97 \\
(2.22)\end{array}$ & 0.249 & $\begin{array}{c}143 \\
(11.05)\end{array}$ & $\begin{array}{c}170 \\
(11.77)\end{array}$ & $\begin{array}{c}313 \\
(11.43)\end{array}$ & 0.553 \\
\hline $\begin{array}{r}\text { Frequent alcohol } \\
\text { intoxication }(3+\text { times })\end{array}$ & $\begin{array}{c}13 \\
(0.58)\end{array}$ & $\begin{array}{c}24 \\
(1.13)\end{array}$ & $\begin{array}{c}37 \\
(0.85)\end{array}$ & 0.050 & $\begin{array}{c}54 \\
(4.17)\end{array}$ & $\begin{array}{c}57 \\
(3.95)\end{array}$ & $\begin{array}{c}111 \\
(4.05)\end{array}$ & 0.765 \\
\hline
\end{tabular}

a Pearson's chi-squared test 
Table 3. Baseline prevalence of eating behaviours, physical activity, and sedentary behaviour in recruited students by study arm

\begin{tabular}{|c|c|c|c|c|c|c|c|c|}
\hline & \multicolumn{4}{|c|}{ Middle schools } & \multicolumn{4}{|c|}{ High schools } \\
\hline & $\begin{array}{c}\text { Intervention } \\
(\mathrm{N}=2384)\end{array}$ & $\begin{array}{c}\text { Control } \\
(\mathrm{N}=2316)\end{array}$ & $\begin{array}{c}\text { Total } \\
(\mathrm{N}=4700)\end{array}$ & $p$-value ${ }^{a}$ & $\begin{array}{l}\text { Intervention } \\
(\mathrm{N}=1389)\end{array}$ & $\begin{array}{c}\text { Control } \\
(N=1563)\end{array}$ & $\begin{array}{c}\text { Total } \\
(\mathrm{N}=2952)\end{array}$ & $\begin{array}{c}\text { p- } \\
\text { value }\end{array}$ \\
\hline \multicolumn{9}{|l|}{ Eating behaviours (n (\%)) } \\
\hline $\begin{array}{r}\text { Fruit consumption } \\
\text { everyday }\end{array}$ & $\begin{array}{c}948 \\
(40.22)\end{array}$ & $\begin{array}{c}951 \\
(41.56)\end{array}$ & $\begin{array}{c}1899 \\
(40.88)\end{array}$ & 0.352 & $\begin{array}{c}474 \\
(34.42)\end{array}$ & $\begin{array}{c}490 \\
(31.69)\end{array}$ & $\begin{array}{c}964 \\
(32.98)\end{array}$ & 0.117 \\
\hline $\begin{array}{r}\text { Vegetables consumption } \\
\text { everyday }\end{array}$ & $\begin{array}{c}820 \\
(34.83)\end{array}$ & $\begin{array}{c}803 \\
(35.10)\end{array}$ & $\begin{array}{c}1623 \\
(34.96)\end{array}$ & 0.852 & $\begin{array}{c}397 \\
(28.94)\end{array}$ & $\begin{array}{c}444 \\
(28.85)\end{array}$ & $\begin{array}{c}841 \\
(28.89)\end{array}$ & 0.959 \\
\hline Breakfast everyday & $\begin{array}{c}1656 \\
(69.99)\end{array}$ & $\begin{array}{c}1617 \\
(70.21)\end{array}$ & $\begin{array}{c}3273 \\
(70.06)\end{array}$ & 0.817 & $\begin{array}{c}820 \\
(59.21)\end{array}$ & $\begin{array}{c}939 \\
(60.35)\end{array}$ & $\begin{array}{c}1759 \\
(59.81)\end{array}$ & 0.529 \\
\hline $\begin{array}{r}\text { Sugar-sweetened drinks } \\
4+\text { times per week }\end{array}$ & $\begin{array}{c}930 \\
(39.73)\end{array}$ & $\begin{array}{c}904 \\
(39.67)\end{array}$ & $\begin{array}{c}1834 \\
(39.70)\end{array}$ & 0.967 & $\begin{array}{c}651 \\
(47.80)\end{array}$ & $\begin{array}{c}742 \\
(48.18)\end{array}$ & $\begin{array}{c}1393 \\
(48.00)\end{array}$ & 0.836 \\
\hline $\begin{array}{r}\text { Crisps and snacks 4+ } \\
\text { times per week }\end{array}$ & $\begin{array}{c}803 \\
(34.87)\end{array}$ & $\begin{array}{c}762 \\
(34.19)\end{array}$ & $\begin{array}{l}1565 \\
(34.53)\end{array}$ & 0.629 & $\begin{array}{c}537 \\
(39.63)\end{array}$ & $\begin{array}{c}594 \\
(38.67)\end{array}$ & $\begin{array}{c}1131 \\
(39.12)\end{array}$ & 0.598 \\
\hline $\begin{array}{r}\text { Cakes and ice creams 4+ } \\
\text { times per week } \\
\text { Physical activity (\%) }\end{array}$ & $\begin{array}{c}866 \\
(37.06)\end{array}$ & $\begin{array}{c}867 \\
(38.30)\end{array}$ & $\begin{array}{c}1733 \\
(37.67)\end{array}$ & 0.386 & $\begin{array}{c}586 \\
(42.93)\end{array}$ & $\begin{array}{c}614 \\
(40.03)\end{array}$ & $\begin{array}{c}1200 \\
(41.39)\end{array}$ & 0.113 \\
\hline At least 60 minutes & & & & & & & & \\
\hline $\begin{array}{r}\text { of physical activity per } \\
\text { day }\end{array}$ & $\begin{array}{c}324 \\
(14.07)\end{array}$ & $\begin{array}{c}327 \\
(14.68)\end{array}$ & $\begin{array}{c}651 \\
(14.37)\end{array}$ & 0.555 & $\begin{array}{c}192 \\
(14.13)\end{array}$ & $\begin{array}{c}238 \\
(15.70)\end{array}$ & $\begin{array}{c}430 \\
(14.96)\end{array}$ & 0.238 \\
\hline $\begin{array}{r}\text { Intense physical activity } \\
\text { per day }\end{array}$ & $\begin{array}{c}162 \\
(6.92)\end{array}$ & $\begin{array}{c}186 \\
(8.18)\end{array}$ & $\begin{array}{l}348 \\
(7.54)\end{array}$ & 0.105 & $\begin{array}{c}85 \\
(6.19)\end{array}$ & $\begin{array}{c}121 \\
(7.92)\end{array}$ & $\begin{array}{l}206 \\
(7.10)\end{array}$ & 0.070 \\
\hline Sedentary behaviour (\%) & & & & & & & & \\
\hline $\begin{array}{r}\text { Watches TV } 3+\text { hours per } \\
\text { day }\end{array}$ & $\begin{array}{c}759 \\
(32.20)\end{array}$ & $\begin{array}{c}743 \\
(32.45)\end{array}$ & $\begin{array}{c}1502 \\
(32.32)\end{array}$ & 0.859 & $\begin{array}{c}464 \\
(33.77)\end{array}$ & $\begin{array}{c}537 \\
(34.80)\end{array}$ & $\begin{array}{c}1001 \\
(34.32)\end{array}$ & 0.558 \\
\hline $\begin{array}{r}\text { Uses computer or } \\
\text { videogames } 3+\text { hours per } \\
\text { day }\end{array}$ & $\begin{array}{c}662 \\
(28.17)\end{array}$ & $\begin{array}{c}676 \\
(29.52)\end{array}$ & $\begin{array}{c}1338 \\
(28.84)\end{array}$ & 0.310 & $\begin{array}{c}597 \\
(43.26)\end{array}$ & $\begin{array}{c}682 \\
(43.94)\end{array}$ & $\begin{array}{c}1279 \\
(43.62)\end{array}$ & 0.710 \\
\hline
\end{tabular}

a Pearson's chi-squared test 
Appendix 1. Intracluster correlation coefficients (ICCS) estimated from baseline data for each outcome variable

\begin{tabular}{|c|c|c|}
\hline Outcome variable & $\begin{array}{l}\text { Middle schools } \\
\text { ICC }(95 \% \mathrm{Cl})\end{array}$ & $\begin{array}{l}\text { High schools } \\
\text { ICC }(95 \% \mathrm{Cl})\end{array}$ \\
\hline \multicolumn{3}{|l|}{ Substance use } \\
\hline Past-30-day smoking & $0.021(0.011$ to 0.041$)$ & $0.086(0.058$ to 0.126$)$ \\
\hline Past-30-day alcohol misuse & $0.018(0.009$ to 0.037$)$ & $0.045(0.026$ to 0.076$)$ \\
\hline \multicolumn{3}{|l|}{ Eating behaviours } \\
\hline Fruit consumption & $0.007(0.002$ to 0.029$)$ & $0.022(0.011$ to 0.044$)$ \\
\hline Vegetables consumption & $0.024(0.014$ to 0.042$)$ & $0.036(0.021$ to 0.060$)$ \\
\hline Breakfast & $0.012(0.005$ to 0.030$)$ & $0.015(0.006$ to 0.037$)$ \\
\hline Sugar-sweetened drinks & $0.026(0.016$ to 0.044$)$ & $0.037(0.022$ to 0.062$)$ \\
\hline Crisps & $0.040(0.027$ to 0.059$)$ & $0.035(0.021$ to 0.060$)$ \\
\hline Cakes and ice creams & $0.017(0.008$ to 0.034$)$ & $0.011(0.003$ to 0.034$)$ \\
\hline \multicolumn{3}{|l|}{ Physical activity } \\
\hline Physical activity for at least one hour & $0.013(0.005$ to 0.030$)$ & $0.031(0.017$ to 0.055$)$ \\
\hline Physical activity leading to being out of breath & $0.007(0.002$ to 0.029$)$ & $0.032(0.019$ to 0.053$)$ \\
\hline Time spent watching TV & $0.034(0.022$ to 0.052$)$ & $0.052(0.033$ to 0.081$)$ \\
\hline Time spent using a computer or videogames & $0.031(0.019$ to 0.049$)$ & $0.041(0.024$ to 0.068$)$ \\
\hline
\end{tabular}

Note: in bold are ICCs greater than the ICC of 0.039 anticipated when carrying out sample size calculations. 